\title{
EXPLORING THE ROLE OF THE SUBSTANTIA NIGRA PARS RETICULATA IN EYE MOVEMENTS
}

\author{
Michele A. Basso ${ }^{1}$ and Marc A. Sommer ${ }^{2}$ \\ ${ }^{1}$ Department of Neuroscience, Ophthalmology and Visual Sciences University of Wisconsin \\ Madison. Madison, WI 53706 USA \\ ${ }^{2}$ Department of Biomedical Engineering, the Center for Cognitive Neuroscience, and the Duke \\ Institute for Brain Sciences, Duke University Durham, North Carolina USA
}

\section{OVERVIEW}

Saccadic eye movements are rapid movements of the eyes that reorient the line of sight. Many regions within the forebrain, midbrain and hindbrain are involved in the generation and control of saccades. Information from the cerebral cortex is sent to the midbrain superior colliculus (colliculus) and pontine nuclei through at least two pathways. One pathway arises from cerebral cortical neurons and targets the colliculus and pons directly (Fries, 1984, Harting et al., 1992). These cortical projection neurons are excitatory and directly influence the colliculus for the generation of voluntary saccades (Segraves and Goldberg, 1987, Sommer and Wurtz, 2000, Paré and Wurtz, 2001, Sommer and Wurtz, 2001, Helminski and Segraves, 2003). A second pathway also arises from neurons in the cerebral cortex and targets the colliculus, but reaches it indirectly, through a series of synapses within nuclei of the basal ganglia (Figure 1a; Selemon and Goldman-Rakic, 1985, 1988, Stanton et al., 1988, Parthasarathy et al., 1992, Weyand and Gafka, 1998). The cortical projection neurons making up this pathway are also excitatory, however most basal ganglia nuclei and in particular its output nuclei have high GABA content (Tepper and Bolam, 2004). Therefore, the signaling from the cortico-basal ganglia-colliculus pathway ultimately results in inhibition or disinhibition of collicular neuronal activity (Figure 1b; Chevalier et al., 1981a, Chevalier et al., 1981b, Chevalier et al., 1984, Chevalier et al., 1985, Chevalier and Deniau, 1990).

Until recently, the role of the basal ganglia in the control of eye movements focused exclusively on the synaptic connection from the caudate nucleus to the dorsolateral substantia nigra pars reticulata (nigra) to the superior colliculus. The nigro-collicular pathway is GABAergic and thus, when this inhibition is removed, the colliculus may send the command to move to the brainstem saccade generating circuits (Moschovakis et al., 1988a, Moschovakis et al., 1988b, Moschovakis et al., 1996, Rodgers et al., 2006) leading to a change in the line of sight. Recent evidence that we review here extends these original findings in important ways. First, in addition to providing a gate for saccades, the GABAergic connection of the nigra to the colliculus may also act to suppress saccades.

(C) 2011 IBRO. Published by Elsevier Ltd. All rights reserved.

Address Correspondence: Michele A. Basso, Department of Neuroscience, University of Wisconsin Madison, 1300 University Avenue Room 127 SMI, Madison, WI 53706, mabasso@wisc.edu.

Publisher's Disclaimer: This is a PDF file of an unedited manuscript that has been accepted for publication. As a service to our customers we are providing this early version of the manuscript. The manuscript will undergo copyediting, typesetting, and review of the resulting proof before it is published in its final citable form. Please note that during the production process errors may be discovered which could affect the content, and all legal disclaimers that apply to the journal pertain. 
Second, the influence of the nigra appears to be widespread in the colliculus, influencing both its inhibitory neurons and output neurons. Hence the nigra may act by influencing patterns of activity across the entire colliculus. Third, recent experiments using electrical stimulation provide evidence that the nigra preferentially influences saccades guided by nonvisual cues compared to those guided by visual cues. Finally, recent recording experiments that ventured outside of the caudate-nigro-collicular pathway suggest more widespread involvement of basal ganglia nuclei, including the globus pallidus, in the generation of saccades. We discuss each of these new results below.

\section{SUBSTANTIA NIGRA PARS RETICULATA - A SACCADIC GATE?}

The relationship between saccadic eye movements and neuronal activity in the nigra was first documented with recordings performed in cat and monkey (Hikosaka and Wurtz, 1983c, b, a, d, Joseph and Boussaoud, 1985). Based on this work, the standard model is that the role of the nigra in saccades is to provide tonic inhibition to the superior colliculus which, when released, permits collicular output neurons to send command signals to the saccade generating machinery in the brainstem (Sparks and Hartwich-Young, 1989, Moschovakis et al., 1996). This model is supported by a number of observations. Electrical stimulation of the colliculus activates nigral neurons antidromically (Hikosaka and Wurtz, 1983d) and electrical stimulation of the nigra evokes inhibitory post-synaptic potentials in collicular output neurons (Moschovakis and Karabelas, 1985). Nigral neurons have GABApositive terminals surrounding the somas of predorsal bundle neurons within the colliculus (Behan et al., 1987, Bickford and Hall, 1992). These anatomical and physiological findings are consistent with the notion that the nigra provides strong synaptic inhibition to the colliculus. Injection of the GABA antagonist, bicuculline, into the colliculus results in irrepressible saccadic eye movements in monkeys (Hikosaka and Wurtz, 1985a). Likewise, injection of the GABA agonist, muscimol, into the nigra also produces irrepressible saccades in monkeys (Hikosaka and Wurtz, 1985b) and orienting head and body movements in cats (Boussaoud and Joseph, 1985). Taken together, these results provide support for an inhibitory influence of the nigra on saccades and therefore, a role for the nigro-collicular pathway in the initiation of saccadic eye movements and orienting movements more generally.

The role of the nigra as a gate for saccade initiation is based on the work described above and also on the well-known decrease in neuronal discharge associated with saccade onset in monkeys (Hikosaka and Wurtz, 1983a) or head movements in cats (Joseph and Boussaoud, 1985). Figure 2a (saccade alignment) shows an example of this characteristic activity profile. However, recent experiments in the cat and the monkey show that visual- or saccade-related modulations of nigral activity can be decreases or increases relative to baseline (Figure 2a, target onset alignment; Handel and Glimcher, 1999, Sato and Hikosaka, 2002, Jiang et al., 2003, Shin and Sommer, 2010). In the cat, neurons that increase their activity for visual stimuli tend to project to the opposite colliculus and have large response fields. In contrast, neurons in the nigra of the cat that decrease their activity for visual stimuli tend to project to the ipsilateral colliculus and have smaller receptive fields (Jiang et al., 2003). These observations led to a recent hypothesis that that the nigra gates or releases inhibition for saccades about to be made but also suppresses or increases inhibition for saccades that would interfere with the goal (Jiang et al., 2003). As a first approximation, this hypothesis is compelling, although there are a few unresolved complications. Whereas the experiments performed by Jiang et al., (2003) were performed in anesthetized cats, in alert monkeys the nigral activity seems more diverse; notably, some neurons have both a burst and a pause (as in Figure 2a). Hence any individual nigral neuron in the monkey is not necessarily a "suppressor" or "releaser" but may exert either influence during different phases of behavior. Also, within the population of nigral neurons, the timing of saccade- 
related modulations varies considerably. For many neurons, saccade-related decreases (or increases) in activity begin before movement initiation, with lead times that range from short (Figure 2a) to long (Figure 2b). For other neurons, the activity begins simultaneous with or after movement initiation (Figure 2c). Although some evidence suggests a role in saccade selection (Basso and Wurtz, 2002), we know little to nothing about the relationship between these different response profiles and saccades. It may be that different neurons play different roles. For example the neurons with discharge modulations occurring before saccade onset may play a role in initiation or suppression of saccades whereas those that show modulations in their discharge during or after saccade onset may play a role in providing feedback about the saccade. Exploring the role of the nigra in feedback or corollary discharge would be an interesting direction for future research. Indeed, recent explorations of the role of the thalamus and the colliculus in forming loop circuits between the cortex and basal ganglia provide a solid anatomical foundation for further electrophysiological and behavior studies (Haber and Calzavara, 2009; McHaffie et al., 2005).

Another observation indicating that the nigral influence on saccades extends beyond a simple gate is that nigral neurons tend to have large response fields (Jiang et al., 2003, Shin and Sommer, 2010). In the cat, this appears particularly for those neurons projecting to the contralateral colliculus (Jiang et al., 2003). This finding suggests that the field of influence of the nigral inhibition is large or that the activity of large numbers of nigral neurons with spatially overlapping response fields is pooled to result in precise saccades. Application of electrical stimulation to the nigra during the generation of memory-guided saccades influences eye movements in all directions (Basso and Liu, 2007). At any one site of stimulation, eye movements made to the same or opposite hemifield could be altered. Consistent with the large response fields of nigral neurons, the electrical stimulation results suggest that the nigra influences large regions of both colliculi.

Evidence that the nigra has a broad influence on collicular neuronal populations is suggested by recent in vitro work. Using a slice preparation of the nigro-collicular pathway in mice that were genetically-modified to express green fluorescent protein in GABAergic neurons of the colliculus, Isa and colleagues tested whether the nigra influenced different neurons of the colliculus or whether the influence of the nigra was restricted only to the output neurons of the colliculus (Kaneda et al., 2008). Stimulation of the dorsolateral nigra produced monosynaptic IPSPs in both GABAergic and non-GABAergic neurons of the intermediate layers of the colliculus. This elegant study reveals that the nigra may also influence the spatiotemporal properties of neuronal activity within the colliculus by regulating inhibitory circuitry (Figure 3).

The role of the intrinsic inhibitory circuitry of the colliculus in behavior is poorly understood, particularly for monkeys (Mize, 1992, Munoz and Istvan, 1998, Behan et al., 2002). However, recent experiments in monkeys are consistent with the recent in vitro work showing a role for the nigra in modulating inhibitory circuits within the colliculus (Basso and Liu, 2007). Trained monkeys performed visually-guided and memory-guided saccades to locations throughout the visual field. On randomly interleaved trials, electrical stimulation was applied to the nigra. The prediction was that this stimulation should increase efferent axonal discharge, further inhibiting the colliculus. Thus, stimulation should impair saccades, suppressing them or at least delaying them. Paradoxically, however, nigral stimulation seemed to facilitate visually-guided saccades: latencies decreased and became less variable. The latencies of memory-guided saccades showed mixed results. A possible explanation for the paradoxical facilitation of visually-guided saccades by nigral stimulation is antidromic activation of collicular neurons. Antidromic activation, via axons, is relatively quick and invariant. If nigral stimulation exclusively induces antidromic volleys in the colliculus that trigger saccadic bursts of activity there, quick and invariant saccade generation would be 
expected. Yet simultaneous recordings of neurons in the superior colliculus together with electrical stimulation of the nigra showed that the activity of collicular neurons was suppressed, as expected from orthodromic, GABA-mediated influences (Figure 4; Liu and Basso, 2008). A more likely explanation, then, is that the nigral stimulation influences inhibitory interneurons in the colliculus, similar to the effects demonstrated by Isa and colleagues. Indeed, work in the avian pallidal-thalamic pathway may shed light on the mechanisms of such a circuit (Person and Perkel, 2005). The pallidal-thalamic pathway, like the nigro-collicular projection, is an important output channel of the basal ganglia. Wholecell patch recordings were made of avian thalamic neurons during application of electrical stimulation in the pallidal nucleus. The electrical stimulation used mimicked realistic synaptic input profiles. These simulated inputs caused precisely timed, single IPSPs and rebound action potentials in thalamic neurons. One can imagine how a similar mechanism might underlie synchronization of collicular bursting activity leading to the reduction in the mean and variability of saccade onset times.

An intriguing finding described in the original studies of monkey nigra suggests that its gating effect on saccades is context dependent. Hikosaka and Wurtz (1983) reported that the neurons in the nigra with reduced activity around the time of saccades had a larger reduction in activity when the saccades were guided by memory than when saccades were guided by vision (Hikosaka and Wurtz, 1983c). Similarly, their inactivation experiments showed a preferential effect on saccades guided by memory compared to those guided by vision (Hikosaka and Wurtz, 1985b). The third main method to support any result in monkey neurophysiology is stimulation, and a recent experiment used that method to test the context dependent role of the nigra (Basso and Liu, 2007). As described above, trained monkeys performed visually-guided and memory-guided saccades with and without electrical stimulation of the nigra. The stimulation occurred at the time of the cue to make a saccade appeared (fixation point off). During visually-guided trials, the directions of the saccades made with electrical stimulation differed little from those made without stimulation. In marked contrast, the directions of the saccades that were guided by memory were considerably altered. With nigral stimulation, the monkeys often made saccades to the wrong location - sometimes even $180^{\circ}$ opposite the instructed location (Figure 5). In some cases monkeys failed to make saccades altogether, as though they forgot where to look.

Three lines of neurophysiological evidence therefore support the hypothesis that the nigra plays a preferential role in generating saccades guided by memory rather than vision. But contradictory evidence has been presented as well. One study, for example, reported that neurons in the nigra are modulated equally for visually-guided or memory-guided eye movements (Bayer et al., 2002). Resolving whether the nigral circuit is task dependent is critical for determining if it plays a cognitive role or is simply an upper-level disinhibitor of saccades akin to the omnipause region of the nucleus raphe interpositus (Evinger et al., 1982, Strassman et al., 1987, Büttner-Ennever and Horn, 1994, Missal and Keller, 2002). It may be that the traditional methods of recording, inactivation, and stimulation are too coarse to provide consistent results; resolution of the controversy may depend on more careful functional dissections of the circuits linking cerebral cortex, caudate, nigra, and colliculus. Different areas of cerebral cortex with differing roles in voluntary versus reflexive saccades (eg., Gaymard et al., 1998) may well feed into different subcircuits through the nigra that mediate those differing task dependencies.

\section{THE SUBSTANTIA NIGRA - MOVEMENT AND COGNITION?}

A larger question is the extent to which the basal ganglia should be considered a motor circuit, as opposed to a cognitive circuit. In light of the nigra's putative preference for memoryguided saccades, and related lines of evidence that the basal ganglia may be 
preferentially involved in movements that are generated by internal rather than external cues (Wichmann and Kliem, 2004, Turner and Anderson, 2005), it may be more accurate to think of the network as communicating cognitive goals to action systems. For example, the effects of nigral stimulation on memory-guided movements discussed above may result not from a role of the nigra in movement per se, but rather from a role in representing spatial memory for movement. We (MAB lab) recently began testing this idea by introducing electrical stimulation during the delay-period of memory-guided and visually-guided saccade tasks. Our preliminary evidence reveals that monkeys mislocalize saccade targets when electrical stimulation of the nigra occurs during the delay-period of memory-guided saccades but not when stimulation occurs during the delay-period of visually-guided saccades. These preliminary results are consistent with a role for the nigra in the maintenance of spatial memory for saccades.

If the basal ganglia are involved in spatial memory for movement, might they also play a role in other cognitive functions? Much recent work focuses on the role of rewards and incentives in modulating the activity of basal ganglia nuclei neurons (for a recent review see Hikosaka et al., 2006). However, other work suggests that the nigra may play a role in events that precede movement initiation such as action choice. In a simple task that manipulated the probability that any one of eight possible stimuli would be selected for a saccade, nigral neurons showed modulations in neuronal activity, primarily pauses as shown in Figure $2 \mathrm{~b}$ and c (Basso and Wurtz, 2002). In the simple selection task, when only one target appeared, nigral neurons showed a maximal pause in activity. This is consistent with the high probability that the stimulus will be selected for a saccade. When multiple stimuli appeared, the pause in activity was reduced, consistent with the reduced probability that any one of the eight stimuli would be the target of the saccade. Thus, nigral neurons reflect changes in the probability that a particular stimulus will be identified as a target for a saccadic eye movement. These neurons signal events that precede saccadic eye movement generation; a parsimonious explanation is that they signal saccade choice. Additionally, more recent work shows that neurons of the caudate nucleus are involved in perceptual decision making (Ding and Gold, 2010). It will be interesting to explore decision-making tasks in the nigra, particularly those that dissociate reward mechanisms.

\section{EYE MOVEMENTS - BEYOND THE NIGRA}

Many advances in our knowledge of basal ganglia circuitry have taken place in recent years. Anatomically based models emphasizing the dichotomy between the direct and indirect striatonigral/ pallidal pathways are being updated with models that emphasize the reciprocal and branching nature of the projections between basal ganglia structures. Similarly, physiological models based on increases and decreases in discharge rates are being replaced with models emphasizing the temporal structure of neuronal discharge properties (Nini et al., 1995, Israel and Bergman, 2008). Results from deep brain stimulation as a treatment for patients with movement disorders, such as Parkinson's disease and dystonia and neuropsychiatric diseases such as obsessive compulsive disorder (Kopell and Greenberg, 2008, Utter and Basso, 2008), provide dramatic support for the increasingly accepted view that the basal ganglia contribute to cognition and even mood and emotion (Alexander et al., 1986).

Studies involving basal ganglia nuclei and eye movements are revealing similar trends. One advance in recent work comes from neuronal recordings in the pallidal nuclei, both the internal and external divisions. It is now clear that both pallidal nuclei exhibit strong modulations in discharge rate in the context of eye movement tasks (Figure 6). Kato and Hikosaka (Kato and Hikosaka, 1993) as well as Yoshida and Tanaka (Yoshida and Tanaka, 2009) showed that neurons in the globus pallidus are modulated during saccades. Other 
work has indicated that the contributions of the different nuclei to aspects of the saccade tasks appear to differ. This is assessed by the temporal relationship between the neuronal activity and the aspect of the behavioral task occurring at that time. For example, neurons in the external division of the pallidum exhibit more activity associated with visual stimuli than neurons in the internal division, which in turn exhibit activity more closely associated with the reward at the end of the saccade. The signals in the external division are similar to those recorded from the nigra in the same monkeys, except sign-reversed: the signals are represented mostly with increases relative to baseline in the external division but decreases relative to baseline in the nigra (Shin and Sommer, 2010). The sign-reversal would be expected from the GABAergic projection from the external division to the nigra and the high baseline firing rates found in both structures. The differences in visual/reward signal content between the external and internal divisions of the globus pallidus likely reflect the different anatomical relationships of the two nuclei. Combining experiments assessing the connectivity of different neurons in different nuclei and their relationship to aspects of saccade tasks together with methods that test causality such as stimulation and inactivation, would be an important direction for future research. It is likely that the pallidal neurons with oculomotor activity make up an oculomotor version of the pallido-thalamo-cortical pathway similar to that seen for limb movements (Alexander et al., 1986). As far as we now there is no pathway from the GPi to the colliculus in mammals although there appears to be one in primitive vertebrates (Stephenson-Jones et al., 2011). How and whether the pallidal activity feeds into the oculomotor circuit via the thalamocortical pathway remains a goal for future research. These new results together with the results of others presented in this review argue strongly that our understanding of the role of the basal ganglia in saccades is still evolving.

\section{CONCLUSIONS AND FUTURE DIRECTIONS}

A recurring theme in this review has been the diversity of signals found in the nigra and other basal ganglia structures. It is clear that the system is more complex than described in early papers. A major challenge is to understand the implications of this diversity at the structure-function level. Is it a general rule that different signals go to different targets, as suggested by the elegant work of Jiang et al., (2003). This is attractive in that it implies a simple channeling of like signals through segregated pathways. Or is information multiplexed to every target? This is intriguing because the microcircuitry of every target is itself diverse, with a multitude of subtargets including inhibitory and excitatory local interneurons in addition to projection neurons. Quite likely, of course, the system makes use of a combination of segregated channels and multiplexing. Making sense of the coding scheme of the basal ganglia's outputs will be an imposing task, but one that could be accomplished with systematic, identified recordings that make used of electrical or optogenetic methods of antidromic and orthodromic stimulation techniques.

More work is also needed to tease out the relative contributions of the various basal ganglia nuclei to eye movements; the traditional view of a dedicated caudate-nigro-colliculus channel for saccades is now outdated, and we need to further dissect the roles of the pallidum and other nuclei such as the subthalamic nucleus to understand their contributions to eye movements and orienting.

As a final note, a long-standing question is whether the nigro-collicular projections themselves form a map representing eye movements. Anatomically, there is evidence in the rodent that specific regions of the nigra target specific regions of the colliculus (Deniau et al, 2007). In the cat it appears that separate populations of neurons target the colliculus on either side of the brain. At the recording and stimulation level in the monkey however, this topography remains elusive. It may be that our methods in the monkey to date lack the sensitivity to measure this topography. The push to develop molecular techniques in 
monkeys to target specific populations of neurons for activation and inactivation will go a long way toward answering these important, unresolved questions.

\section{Acknowledgments}

The work in our laboratories is supported by NIH EY13692, EY019663, NS065776 (MAB), EY017592 (MAS), NCRR P51 RR000167 awarded to the Wisconsin National Primate Research Center, and an NIH core grant in Vision Research P30 EY0166665

\section{References}

Alexander GE, DeLong MR, Strick Pl. Crutcher and DeLong (1986). Parallel organization of functionally segregated circuits linking basal ganglia and cortex. Annual Review of Neuroscience. 1986; 9:357-381.

Basso MA, Liu P. Context-dependent effects of substantia nigra stimulation on eye movements. J Neurophysiol. 2007; 97:4129-4142. [PubMed: 17392414]

Basso MA, Wurtz RH. Neuronal activity in substantia nigra pars reticulata during target selection. Journal of Neuroscience. 2002; 22:1883-1894. [PubMed: 11880518]

Bayer HM, Handel A, Glimcher PW. Eye position and memory saccade related responses in substantia nigra pars reticulata. Experimental Brain Research. 2002; 154:428-441.

Behan M, Lin CS, Hall WC. The nigrotectal projection in the cat: an electron microscope autoradiographic study. Neuroscience. 1987; 21:529-539. [PubMed: 3039404]

Behan M, Steinhacker K, Jeffrey-Borger S, Meredith MA. Chemoarchitecture of GABAergic neurons in the ferret superior colliculus. J Comp Neurol. 2002; 452:334-359. [PubMed: 12355417]

Bickford ME, Hall WC. The nigral projection to predorsal bundle cells in the superior colliculus of the rat. J Comp Neurol. 1992; 319:11-33. [PubMed: 1375604]

Boussaoud D, Joseph JP. Role of the cat substantia nigra pars reticulata in eye and head movements. II. Effects of local pharmacological injections. Exp Brain Res. 1985; 57:297-304. [PubMed: 2982633]

Büttner-Ennever, JA.; Horn, AKE. Neuroanatomy of saccadic omnipause neurons in nucleus raphe interpositus. In: Fuchs, AF., et al., editors. Contemporary Ocular Motor and Vestibular Research: A Tribute to David A Robinson. Stuttgart: Thieme; 1994. p. 488-495.

Chevalier G, Deniau JM. Disinhibition as a basic process in the expression of striatal functions. Trends Neurosci. 1990; 13:277-280. [PubMed: 1695403]

Chevalier G, Deniau JM, Thierry AM, Feger J. The nigro-tectal pathway. An electrophysiological reinvestigation in the rat. Brain Res. 1981a; 213:253-263. [PubMed: 7248757]

Chevalier G, Thierry AM, Shibazaki T, Feger J. Evidence for a GABAergic inhibitory nigrotectal pathway in the rat. Neurosci Lett. 1981b; 21:67-70. [PubMed: 7207871]

Chevalier G, Vacher S, Deniau JM. Inhibitory nigral influence on tectospinal neurons, a possible implication of basal ganglia in orienting behavior. Exp Brain Res. 1984; 53:320-326. [PubMed: 6705865]

Chevalier G, Vacher S, Deniau JM, Desban M. Disinhibition as a basic process in the expression of striatal functions. I. The striato-nigral influence on tecto-spinal/tecto-diencephalic neurons. Brain Res. 1985; 334:215-226. [PubMed: 2859912]

Deniau JM, Mailly P, Maurice N, Charpier S. The pars reticulata of the substantia nigra: a window to the basal ganglia. Progress in Brain Research. 2007; 160:151-172. [PubMed: 17499113]

Ding L, Gold JI. Caudate encodes multiple computations for perceptual decisions. J Neurosci. 2010; 30:15747-15759. [PubMed: 21106814]

Evinger C, Kaneko CRS, Fuchs AF. Activity of omnipause neurons in alert cats during saccadic eye movements and visual stimuli. J Neurophysiol. 1982; 47:827-844. [PubMed: 7086471]

Fries W. Cortical projections to the superior colliculus in the macaque monkey: A retrograde study using horseradish peroxidase. J Comp Neurol. 1984; 230:55-76. [PubMed: 6096414]

Gaymard B, Ploner CJ, Rivaud S, Vermersch AI, Pierrot-Deseilligny C. Cortical control of saccades. Experimental Brain Research. 1998; 123:159-163. 
Haber SN, Calzavara R. The cortico-basal ganglia integrative network:The role of the thalamus. Brain Research Bulletin. 2009; 78:69-74. [PubMed: 18950692]

Handel A, Glimcher PW. Quantitative analysis of substantia nigra pars reticulata activity during a visually guided saccade task. J Neurophysiol. 1999; 82:3458-3475. [PubMed: 10601475]

Harting JK, Updyke BV, Van Lieshout DP. Corticotectal projections in the cat: anterograde transport studies of twenty-five cortical areas. Journal of Comparative Neurology. 1992; 324:379-414. [PubMed: 1401268]

Helminski JO, Segraves MA. Macaque Frontal Eye Field Input to Saccade-Related Neurons in the Superior Colliculus. J Neurophysiol. 2003; 90:1046-1062. [PubMed: 12736234]

Hikosaka O, Nakamura K, Nakahara H. Basal ganglia orient eyes to reward. J Neurophysiol. 2006; 95:567-584. [PubMed: 16424448]

Hikosaka O, Wurtz RH. Visual and oculomotor functions of monkey substantia nigra pars reticulata. I. Relation of visual and auditory responses to saccades. Journal of Neurophysiology. 1983a; 49:1230-1253. [PubMed: 6864248]

Hikosaka O, Wurtz RH. Visual and oculomotor functions of monkey substantia nigra pars reticulata. II. Visual responses related to fixation of gaze. Journal of Neurophysiology. 1983b; 49:12541267. [PubMed: 6864249]

Hikosaka O, Wurtz RH. Visual and oculomotor functions of monkey substantia nigra pars reticulata. III. Memory-contingent visual and saccade responses. Journal of Neurophysiology. 1983c; 49:1268-1284. [PubMed: 6864250]

Hikosaka O, Wurtz RH. Visual and oculomotor functions of monkey substantia nigra pars reticulata. IV. Relation of substantia nigra to superior colliculus. Journal of Neurophysiology. 1983d; 49:1285-1301. [PubMed: 6306173]

Hikosaka O, Wurtz RH. Modification of saccadic eye movements by GABA-related substances. I. Effect of muscimol and bicuculline in monkey superior colliculus. Journal of Neurophysiology. 1985a; 53:266-291. [PubMed: 2983037]

Hikosaka O, Wurtz RH. Modification of saccadic eye movements by GABA-related substances. II. Effects of muscimol in monkey substantia nigra pars reticulata. Journal of Neurophysiology. 1985b; 53:292-308. [PubMed: 2983038]

Israel Z, Bergman H. Pathophysiology of the basal ganglia and movement disorders: from animal models to human clinical applications. Neurosci Biobehav Rev. 2008; 32:367-377. [PubMed: 17949812]

Jiang H, Stein BE, McHaffie JG. Opposing basal ganglia processes shape midbrain visuomotor activity bilaterally. Nature. 2003; 423:982. [PubMed: 12827201]

Joseph JP, Boussaoud D. Role of the cat substantia nigra pars reticulata in eye and head movements. I. Neural activity. Exp Brain Res. 1985; 57:286-296. [PubMed: 4038661]

Kaneda K, Isa K, Yanagawa Y, Isa T. Nigral inhibition of GABAergic neurons in mouse superior colliculus. J Neurosci. 2008; 28:11071-11078. [PubMed: 18945914]

Kato, M.; Hikosaka, O. Function of the indirect pathway in the basal ganglia oculomotor system: Visuo-oculomotor activities of external pallidum neurons. Segawa, M.; Nomura, Y., editors. Tokyo, Japan: 1993. p. 178-187.

Kopell BH, Greenberg BD. Anatomy and physiology of the basal ganglia: implications for DBS in psychiatry. Neurosci Biobehav Rev. 2008; 32:408-422. [PubMed: 17854894]

Liu P, Basso MA. Substantia nigra stimulation influences monkey superior colliculus neuronal activity bilaterally. J Neurophysiol. 2008; 100:1098-1112. [PubMed: 18579662]

McHaffie JG, Stanford TR, Stein BE, Coizet V, Redgrave P. Subcortical loops through the basal ganglia. Trends in Neurosciences. 2005; 28(8):401-407. [PubMed: 15982753]

Mikula, S.; Stone, JM.; Berman, AL.; Jones, EG. A digital stereotaxic atlas of the brain of the monkey, Macaca mulatta. Center for Neuroscience, University of California, Davis and University of Wisconsin, Madison Supported by Human Brain Project Grant Number MH/DA 52154 from the National Institutes of Health, United States Public Health Service;

Missal M, Keller EL. Common Inhibitory Mechanism for Saccades and Smooth-Pursuit Eye Movements. J Neurophysiol. 2002; 88:1880-1892. [PubMed: 12364514] 
Mize RR. The organization of GABAergic neurons in the mammalian superior colliculus. Prog Brain Res. 1992; 90:219-248. [PubMed: 1321459]

Moschovakis AK, Karabelas AB. Observations on the somatodendritic morphology and axonal trajectory of intracellularly HRP-labeled efferent neurons located in the deeper layers of the superior colliculus of the cat. J Comp Neurol. 1985; 239:276-308. [PubMed: 4044941]

Moschovakis AK, Karabelas AB, Highstein SM. Structure-function relationships in the primate superior colliculus. I. Morphological classification of efferent neurons. J Neurophysiol. 1988a; 60:232-262. [PubMed: 3404219]

Moschovakis AK, Karabelas AB, Highstein SM. Structure-function relationships in the primate superior colliculus. II. Morphological identity of presaccadic neurons. J Neurophysiol. 1988b; 60:263-302. [PubMed: 3404220]

Moschovakis AK, Scudder CA, Highstein SM. The microscopic anatomy and physiology of the mammalian saccadic system. Prog Neurobiol. 1996; 50:133-254. [PubMed: 8971981]

Munoz DP, Istvan PJ. Lateral inhibitory interactions in the intermediate layers of the monkey superior colliculus. J Neurophysiol. 1998; 79:1193-1209. [PubMed: 9497401]

Nini A, Feingold A, Slovin H, Bergman H. Neurons in the globus pallidus do not show correlated activity in the normal monkey, but phase-locked oscillations appear in the MPTP model of parkinsonism. J Neurophysiol. 1995; 74:1800-1805. [PubMed: 8989416]

Paré M, Wurtz RH. Progression in Neuronal Processing for Saccadic Eye Movements From Parietal Cortex Area LIP to Superior Colliculus. Journal of Neurophysiology. 2001; 85:2545-2562. [PubMed: 11387400]

Parthasarathy HB, Schall JD, Graybiel AM. Distributed but convergent ordering of corticostriatal projections: analysis of the frontal eye field and the supplementary eye field in the macaque monkey. J Neurosci. 1992; 12:4468-4488. [PubMed: 1279139]

Person AL, Perkel DJ. Unitary IPSPs drive precise thalamic spiking in a circuit required for learning. Neuron. 2005; 46:129-140. [PubMed: 15820699]

Rodgers CK, Munoz DP, Scott SH, Pare M. Discharge Properties of Monkey Tectoreticular Neurons. J Neurophysiol. 2006; 95:3502-3511. [PubMed: 16641382]

Sato M, Hikosaka O. Role of primate substantia nigra pars reticulata in reward-oriented saccadic eye movement. J Neurosci. 2002; 22:2363-2373. [PubMed: 11896175]

Segraves MA, Goldberg ME. Functional properties of corticotectal neurons in the monkey's frontal eye field. J Neurophysiol. 1987; 58:1387-1419. [PubMed: 3437337]

Selemon LD, Goldman-Rakic PS. Longitudinal topography and interdigitation of corticostriatal projections in the rhesus monkey. J Neurosci. 1985; 5:776-794. [PubMed: 2983048]

Selemon LD, Goldman-Rakic PS. Common cortical and subcortical targets of the dorsolateral prefrontal and posterior parietal cortices in the rhesus monkey: Evidence for a distributed neural network subserving spatially guided behavior. J Neurosci. 1988; 8:4049-4068. [PubMed: 2846794]

Shin S, Sommer MA. Activity of Neurons in Monkey Globus Pallidus During Oculomotor Behavior Compared With That in Substantia Nigra Pars Reticulata. J Neurophysiol. 2010; 103:1874-1887. [PubMed: 20107133]

Sommer MA, Wurtz RH. Composition and topographic organization of signals sent from the frontal eye field to the superior colliculus. J Neurophysiol. 2000; 83:1979-2001. [PubMed: 10758109]

Sommer MA, Wurtz RH. Frontal Eye Field Sends Delay Activity Related to Movement, Memory, and Vision to the Superior Colliculus. Journal of Neurophysiology. 2001; 85:1673-1685. [PubMed: 11287490]

Sparks DL, Hartwich-Young R. The deep layers of the superior colliculus. Rev Oculomot Res. 1989; 3:213-255. [PubMed: 2486324]

Stanton GB, Goldberg ME, Bruce CJ. Frontal eye field efferents in the macaque monkey: I. Subcortical pathways and topography of striatal and thalamic terminal fields. J Comp Neurol. 1988; 271:473-492. [PubMed: 2454970]

Strassman A, Evinger C, McCrea RA, Baker RG, Highstein SM. Anatomy and physiology of intracellularly labelled omnipause neurons in the cat and squirrel monkey. Exp Brain Res. 1987; 67:436-440. [PubMed: 3622701] 
Stephenson-Jones M, Samuelsson E, Ericsson J, Robertson B, Grillner S. Evolutionary conservation of the basal ganglia as a common vertebrate mechanism for action selection. Current Biology. 2011; 21:1081-1091. [PubMed: 21700460]

Tepper JM, Bolam JP. Functional diversity and specificity of neostriatal interneurons. Current Opinion in Neurobiology. 2004; 14:685-692. [PubMed: 15582369]

Turner RS, Anderson ME. Context-dependent modulation of movement-related discharge in the primate globus pallidus. J Neurosci. 2005; 25:2965-2976. [PubMed: 15772356]

Utter AA, Basso MA. The basal ganglia: an overview of circuits and function. Neurosci Biobehav Rev. 2008; 32:333-342. [PubMed: 17202023]

Weyand TG, Gafka AC. Corticostriatal and corticotectal neurons in area 6 of the cat during fixation and eye movements. Vis Neurosci. 1998; 15:141-151. [PubMed: 9456513]

Wichmann T, Kliem MA. Neuronal Activity in the Primate Substantia Nigra Pars Reticulata During the Performance of Simple and Memory-Guided Elbow Movements. Journal of Neurophysiology. 2004; 91:815-827. [PubMed: 14762150]

Yoshida A, Tanaka M. Enhanced modulation of neuronal activity during antisaccades in the primate globus pallidus. Cereb Cortex. 2009; 19:206-21. [PubMed: 18477689] 
Highlights

SUBSTANTIA NIGRA PARS RETICULATA - A SACCADIC GATE?

THE SUBSTANTIA NIGRA - MOVEMENT OR COGNITION?

EYE MOVEMENTS - BEYOND THE SUBSTANTIA NIGRA 
The Basal Ganglia and Saccades - A Simplified Circuit

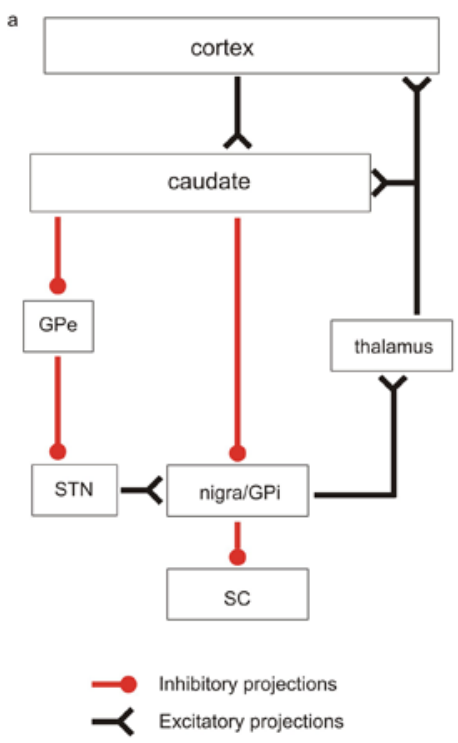

b

caudate

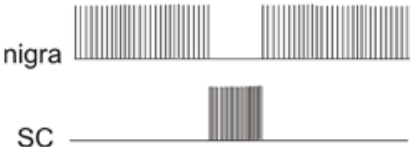

Figure 1.

Simplified schematic diagram of major basal ganglia nuclei and their functional relationship to saccadic eye movements. a. Box diagram of the connections between basal ganglia nuclei. Red lines terminating in filled circles indicate inhibitory connections. Black lines terminating in inverted arrowheads indicate excitatory connections. b. Schematic discharge profiles of neuronal activity in basal ganglia nuclei, adapted from traditional models. Each vertical line indicates the time of occurrence of an action potential. GPi $=$ globus pallidus internal division; $\mathrm{GPe}=$ globus pallidus external division; $\mathrm{SC}=$ superior colliculus; nigra = substania nigra pars reticulata; $\mathrm{STN}=$ subthalamic nucleus. 

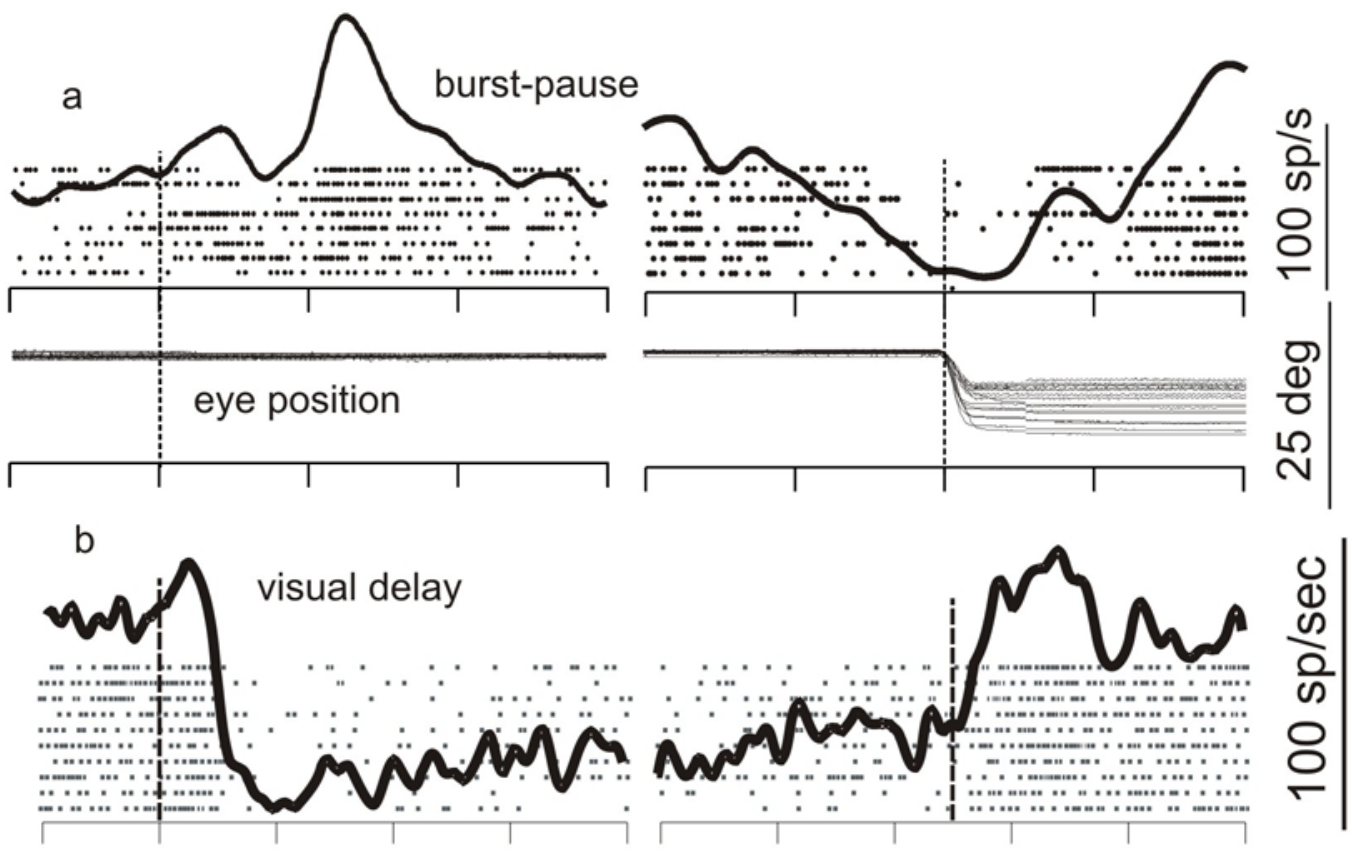

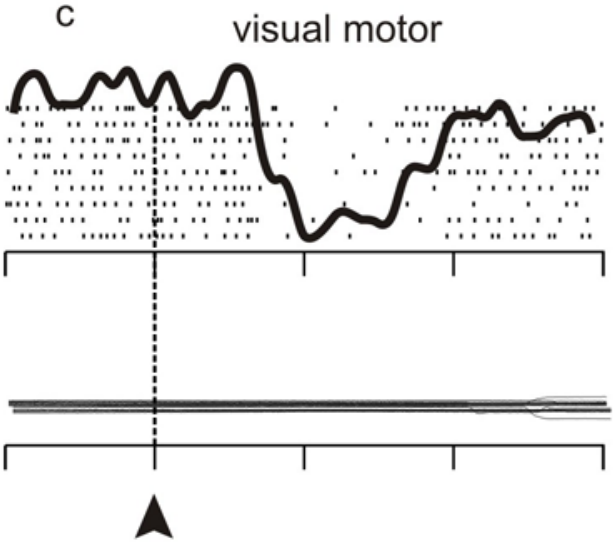

target onset

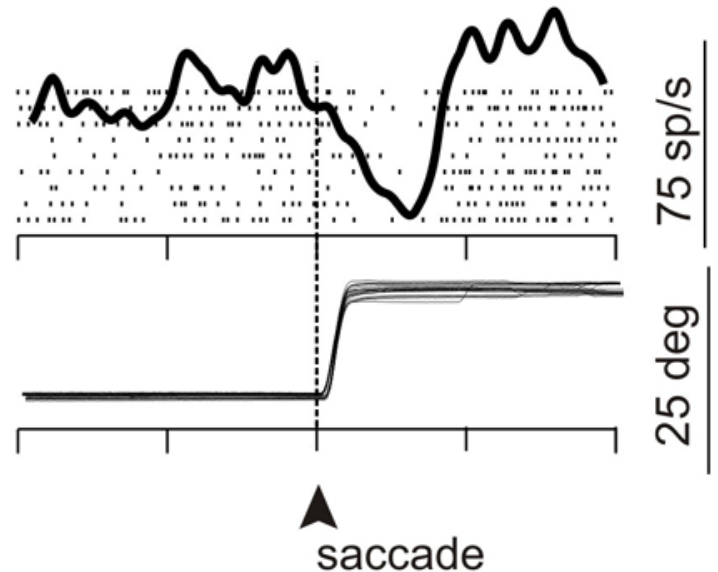

Figure 2.

Activity of nigral neurons around the time of saccades. a-c. The discharges of three neurons recorded from the nigra in an alert monkey that performed a delayed-saccade task. Each tick indicates the time of occurrence of one action potential. Each row of ticks indicates a single trial in which a correct saccade was made to a visual stimulus that was located in the periphery of the visual field. The envelope of activity overlain on the raster plot shows the spike density function. Data are aligned on events in the task as indicated by the upward arrow and the dashed, vertical line. At left, data are aligned on the onset of the visual target; at right, data are on the onset of the saccade. H Eye, horizontal eye position; V Eye, vertical eye position. a. Example of a neuron that shows an increase for the onset of a target and reduces its discharge well in advance of the onset of a saccade. b. Example of a neuron that reduces its discharge well before the onset of a saccade. c. Example of a neuron that reduces its discharge for the onset of visual stimuli and then again at the time of saccade onset. 


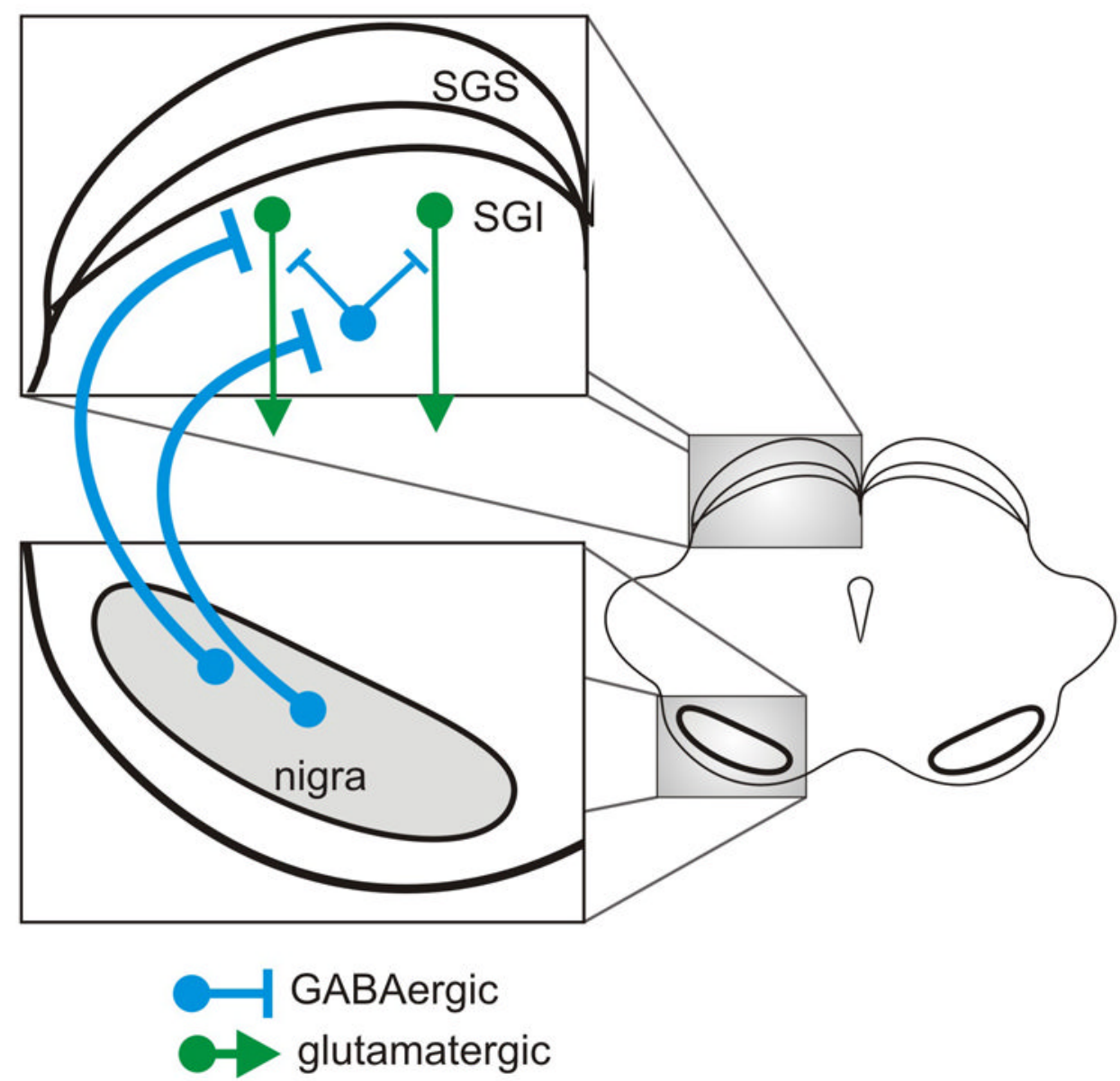

Figure 3.

Schematic representation of the connections from the nigra to the superior colliclus as recently identified by Kaneda et al., 2008. Blue circles and lines indicate inhibitory GABAergic neurons and connections. Green circles and lines indicate excitatory glutaminergic neurons and connections. Downward arrows indicate that these neurons project out of the colliculus and travel in the predorsal bundle neurons en route to the brainstem saccade generating machinery. It is unknown whether the connections from the nigra to the colliculus targeting the different neuron types in the colliculus arise from different neurons in the nigra. They were drawn separately for clarity. SGS = superficial layer of the colliculus, stratum griseum superficiale; SGI = intermediate layers of the colliculus, stratum griseum intermediale. 

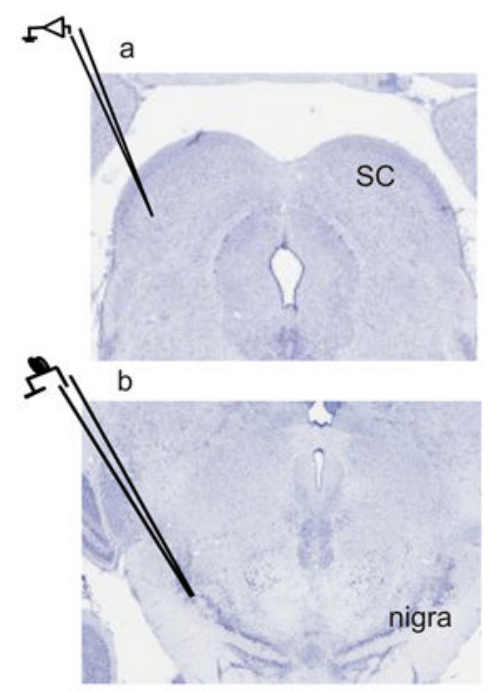

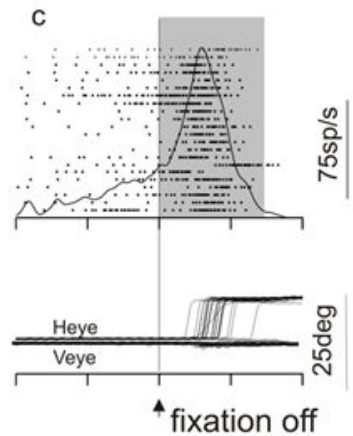

d

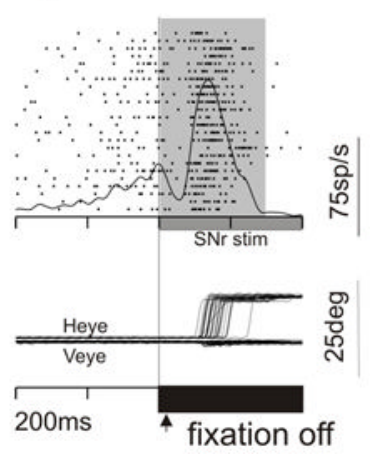

Figure 4.

Stimulation of the nigra transiently suppresses activity in the colliculus. a. Coronal section through the midbrain of a monkey stained for cresyl violet showing the colliculus and the recording electrode. b. Same as in a showing the nigra and the stimulating electrode. c. An example recording from a collicular neuron without nigral stimulation. Each tick is the time of occurrence of an action potential. Each row is a trial. The spike density function averages the activity across all trials. The trace is aligned on the fixation point offset, which was the cue to make the saccade. d. Same as in c except with stimulation of the nigra. The onset and duration of the stimulation is shown as the filled black horizontal bar. Heye, horizontal eye position. Veye, vertical eye position. 
a

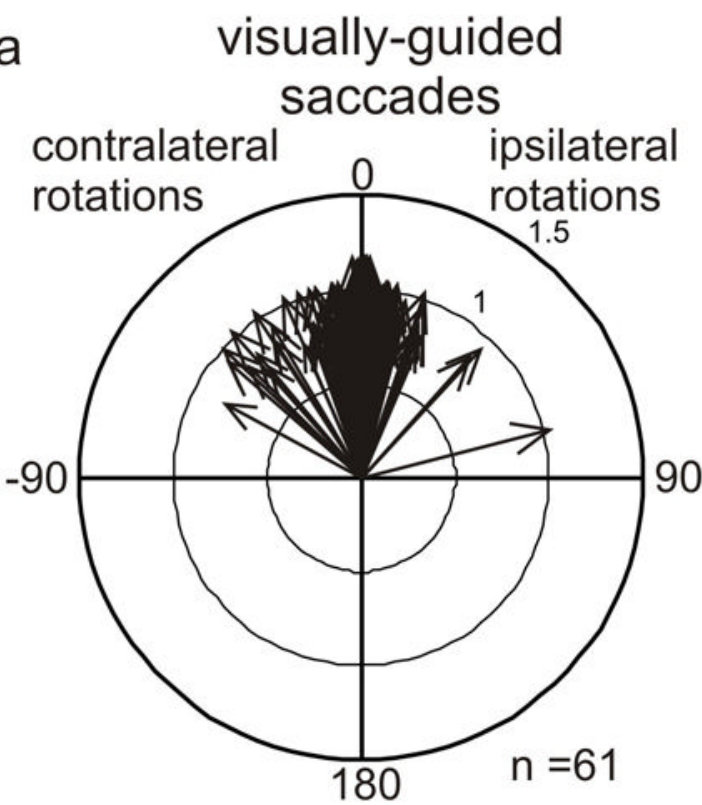

b
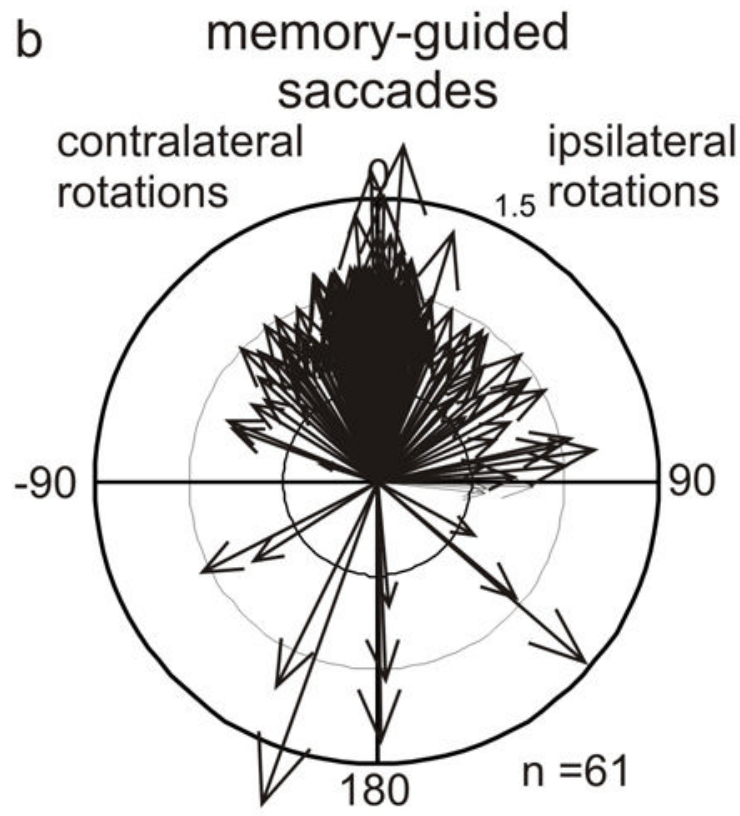

Figure 5.

Electrical stimulation of the nigra influences saccades guided by memory. Polar plots of stimulation effects resulting from $n=61$ stimulation sites in three monkeys. a. Visually guided saccades. b. Memory-guided saccades. Each arrow shows a difference vector for the eye movements made with and without stimulation. An arrow pointing at $0^{\circ}$ indicates that there was no change in the direction of the eye movement with nigral stimulation. An arrow pointing at $180^{\circ}$ indicates that the eye movement with stimulation was in the opposite direction than the eye movement without stimulation. The lengths of the arrows indicate whether the saccade amplitude was larger or smaller with stimulation compared to without. For an arrow of length one there was no change in saccade amplitude. For an arrow with length $<1$ the saccade was hypometric compared to the saccade made without stimulation. For an arrow with length $>1$ the saccade was hypermetric with stimulation compared to without. Contralateral and ipsilateral are relative to the side of stimulation. Modified from Basso and Liu, 2007. 

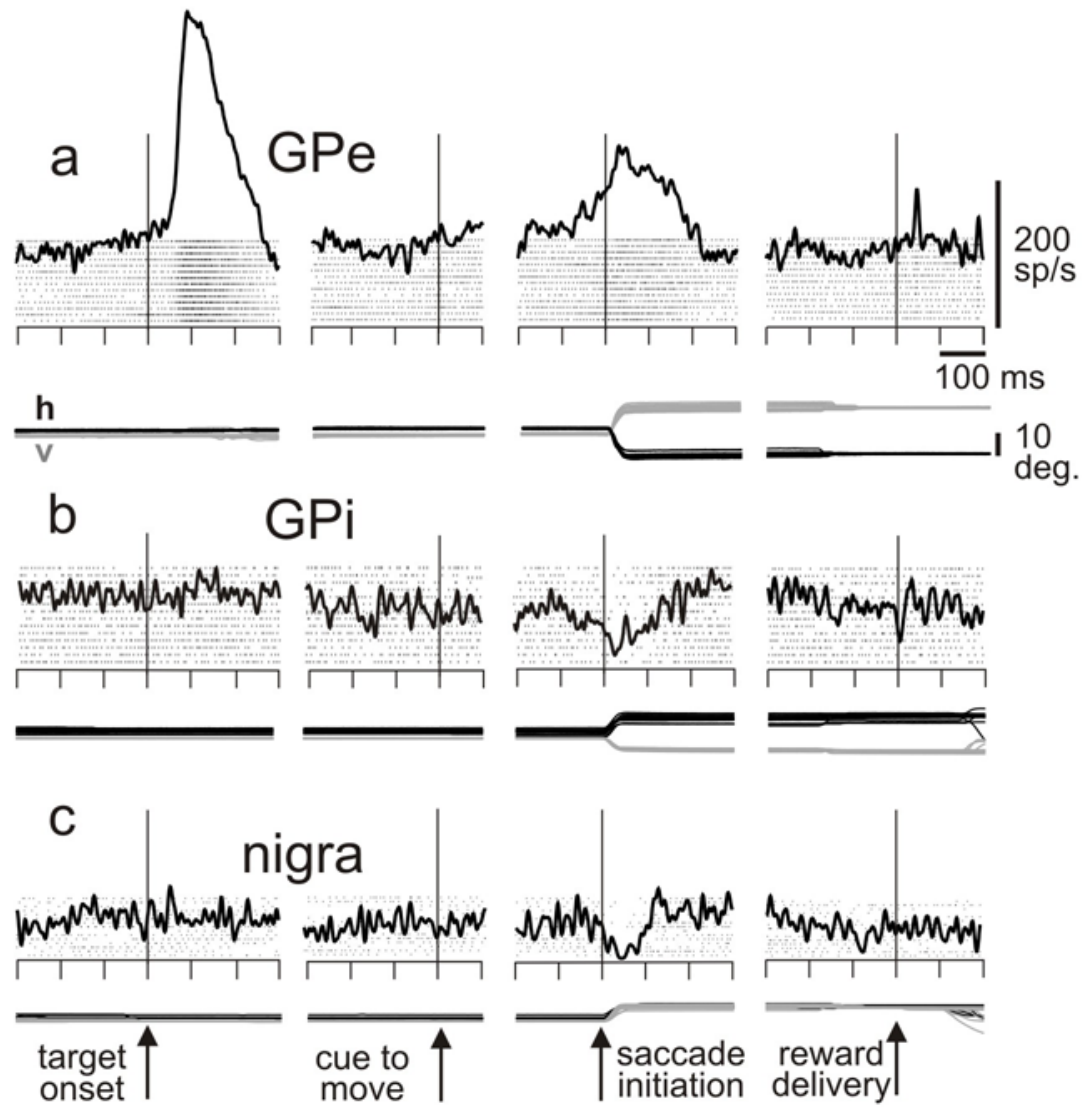

Figure 6.

Saccade-related activity in example neurons from the a. external division of the globus pallidus, $b$. internal division of the globus pallidus, and c. nigra. The monkey was performing a memory-guided saccade task: monkey fixates a spot, a target is flashed in the response field for $50 \mathrm{~ms}$, a delay of 500-1000 ms ensues, the fixation spot disappears (cue to move), the monkey makes a saccade to the remembered location of the target, and liquid reward is delivered for correct performance. Data are aligned as noted. h, v: horizontal and vertical components of eye position. Scales at top right. Modified from Shin and Sommer, 2010. 